\title{
Dampak Kemiringan Dinding Silo Terhadap Distribusi Tegangan Dinding pada Corrugated Steel Silo Berkapasitas 4650 Ton
}

\author{
Susilo Adi Widyanto ${ }^{\mathrm{a}, *}$, Sukamta $^{\mathrm{b}}$, Yurianto ${ }^{\mathrm{a}}$, Agus Suprihanto $^{\mathrm{a}}$ \\ ${ }^{a}$ Departemen Teknik Mesin, Fakultas Teknik, Universitas Diponegoro \\ ${ }^{\mathrm{b}}$ Departemen Teknik Sipil, Fakultas Teknik, Universitas Diponegoro \\ Jl. Prof Sudarto SH, Tembalang, Semarang, Indonesia \\ *E-mail: susilo70@yahoo.com
}

\begin{abstract}
Silo construction is designed to store grains. Ideally the vertical axis of the silo and the wall is perpendicular to the base plate, so that the wall is only loaded by radial force due to the height of the column. The slope of the silo construction causes a load combination on the wall in the direction of the slope. This paper discusses the effect of the slope of silo construction toward the force acting on the wall. Capacity of the observed silo is 4650 tons, with the diameter of $19 \mathrm{~m}$ and the height of $20 \mathrm{~m}$. FEM modeling results shown that the stress distribution of the walls with different thicknesses is relatively larger than the occurence stress on the double wall of the bottom of silo. Maximum stress occurs on the bolt joint area between the wall and the stiffener. At the slope of 10o the maximum stress of wall is around of $45 \mathrm{~kg} / \mathrm{mm} 2$ on the double wall as well as on the location with the different thickness.
\end{abstract}

Keywords: Silo; silo wall; stiffener; stress distribution

\section{Abstrak}

Konstruksi silo dirancang untuk menyimpan butiran. Idealnya sumbu vertikal silo maupun dindingnya tegak lurus terhadap bidang dasarnya sehingga beban dinding hanya berupa gaya radial akibat ketinggian kolomnya. Miringnya konstruksi silo menyebabkan terjadinya beban gabungan pada dinding pada arah kemiringannya. Paper ini membahas pengaruh kemiringan konstruksi silo pada gaya yang bekerja pada dinding. Silo yang diobservasi dengan kapasitas penyimpanan sebesar 4650 ton, dengan diameter 19 m dengan ketinggian 20 m. Dari hasil pemodelan FEM, distribusi tegangan pada dinding yang berbeda ketebalannya relatif lebih besar dibandingkan tegangan yang terjadi pada dinding ganda pada bagian dibawahnya. Tegangan maksimum terjadi pada daerah sambungan baut antara dinding dan stiffener. Pada kemiringan 10o tegangan maksimum dinding mencapai sekitar $45 \mathrm{~kg} / \mathrm{mm} 2$ baik pada dinding ganda maupun di lokasi dinding yang berbeda ketebalannya.

Kata kunci: Silo; dinding silo; stiffener; distribusi tegangan

\section{Pendahuluan}

Miringnya konstruksi silo dapat berdampak pada terjadinya kegagalan dalam pengoperasiannya. Kemiringan silo dapat disebabkan dengan bergesernya sumbu vertikal silo dimana paneluruh dindingnya mengalami kecenderungan pola kemiringan yang sama atau dapat juga disebabkan karena miringnya profil dinding pada bidang ukurnya. Kemiringan silo yang menyangkut sumbu vertikalnya kemungkinan besar disebabkan karena turunnya sistem pondasi yang bersifat lokal (tidak merata). Kondisi ini ditandai dengan kesamaan trend kemiringan dengan silo-silo yang lain bila silo-silo tersebut diletakkan pada satu sistem pondasi.

Miringnya konstruksi silo menyebabkan terjadinya pergeseran titik pusat masa pada saat silo terisi. Bila struktur dinding cukup kuat menahan beban distribusi massa isi silo, maka pergeseran titik pusat masa berpotensi menyebabkan robohnya struktur silo setelah kemiringan melewati batas kritisnya. Namun bila struktur dinding relatif lemah, kemiringan silo dapat menyebabkan lepasnya dinding silo dari struktur stiffenernya.

Pada saat dibebani, dinding silo mengalami deformasi yang menyebabkan terjadinya perbesaran diameter. Pada awalnya desain silo didasarkan pada asumsi bahwa bulk solid bersifat seperti liquid. Namun sesungguhnya granular material dapat menahan gaya geser static. Sifat kohensif suatu material dapat membentuk pola aliran steady tertentu. [1] Goodey [2] menyatakan bahwa distribusi tekanan dalam arah horisontal memenuhi fungsi hiperbolic. Sedangkan dalam arah vertikalnya, koefisien tekanan besarnya bervariasi terhadap kedalaman dan tergantung pada kekakuan relatif dari jenis serbuk dan dinding silo.

Prediksi tekanan dinding didasarkan pada keseimbangan gaya pada irisan horisontal yang diakibatkan oleh granular solid yang disimpan [3] dan asumsi harga konstanta untuk rasio tekanan lateralnya yang merupakan rasio tekanan rata-rata pada dinding yang menyebabkan tegangan vertikal dalam granular solid di berbagai level [4-6]. 
Gesekan dinding merupakan faktor penting dalam penentuan tekanan pada dinding. Airy [7] telah melakukan ivestigasi untuk menentukan koefisien gesekan antara grain dan material dinding. Sedangkan Jamiesen (1904) [8] telah melakukan serangkaian grain pressure tests untuk model silo lingkaran, bujur sangkat dan persegi panjang yang dibangun dari material kayu dan baja. Reimberts [9] melakukan pengujian pada bins dengan memvariasikan ukurannya sehingga diperoleh formusi untuk tekanan lateral dan tekanan vertikal yang bekerja pada dinding dan lantai.

Pada konstruksi silo dengan dinding diskontinyu dimana sambungan antar panel dinding menggunakan sambungan baut, penggelembungan dinding silo bisa terjadi akibat kendornya baut pengikat antar dinding sehingga menyebabkan terjadinya gerak relatif pada bidang overlapnya. Distribusi torsi pengencangan baut yang tidak merata menyebabkan terjadinya penggelembungan dinding yang tidak simetris. Kendornya sambungan baut antar panel dinding juga berpotensi menyebabkan robeknya dinding akibat tegangan geser yang terjadi antara baut dengan dinding. Sekalipun sebagian besar kerusakan silo terjadi karena tekanan yang bekerja pada dinding yang besarnya tidak terprediksi ketika grain bergerak. Beberapa bentuk kegagalan silo diantaranya adalah gagalnya sistem pondasi, kecepatan pengisian silo yang menyebabkan tekanan berlebih, gaya gesek, tekanan pada dinding silo bagian bawah dan kondisi saluran keluaran grain yang abnormal. Ketidak-homogenan grain menyebabkan sulitnya menentukan tekanan yang terjadi pada dinding silo [10].

Miringnya dinding atau konstruksi silo secara kepaneluruhkan berpengaruh pada kondisi tekanan dinding yang yang tidak merata. Pada sisi kemiringannya, dinding panelain mengalami gaya desak grain dalam arah radial, juga menanggung beban gravitasi grain yang ada di atasnya. Paper ini membahas pengaruh kemiringan dinding silo terhadap distribusi tegangan dindingnya yang dilakukan dengan analisis FEM. Model dinding yang digunakan terdiri dari dua jenis yang berada pada ketinggian 0-2m dengan ketebalan 2x2,5 mm dan dinding pada ketinggian 1-3m dengan ketebalan bervariasi yaitu 2x2,5 dan 1x2,5 mm. Pemodelan dilakukan dengan memvariasikan sudut kemiringan dinding.

\section{Metode Penelitian}

Konstruksi silo yang diinvestigasi diuraikan sebagai berikut:

\subsection{Struktur Dinding}

Struktur dinding terbuat dari galvanized sheet plate bergelombang (corrugated) dengan ketebalan 2,5 mm. Dari hasil pengukuran, panjang dan lebar setiap panel dinding adalah 3000 x 1100 mm. Profil dinding yang digunakan pada konstruksi silo seperti ditunjukkan dalam Gambar 1. Karena pertimbangan besarnya gaya desak material tersimpan dalam silo, dinding silo pada posisi paling bawah pada ketinggian 0-2 m menggunakan dinding rangkap (2x2,5 mm), sedangkan panel dinding pada bagian di atasnya menggunakan dinding tunggal.

Sambungan antar panel dinding menggunakan baut M12 yang dipasang berjajar secara parallel, sehingga setiap sambungan menggunakan 38 baut dengan luasan overlap 1000 x 95 mm. Formasi baut pengikat antar panel dinding dan stiffner seperti ditunjukkan dalam Gambar 2.

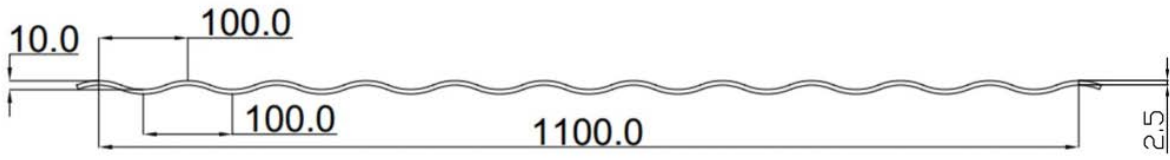

Gambar 1. Profil dinding yang digunakan dalam Konstruksi silo.

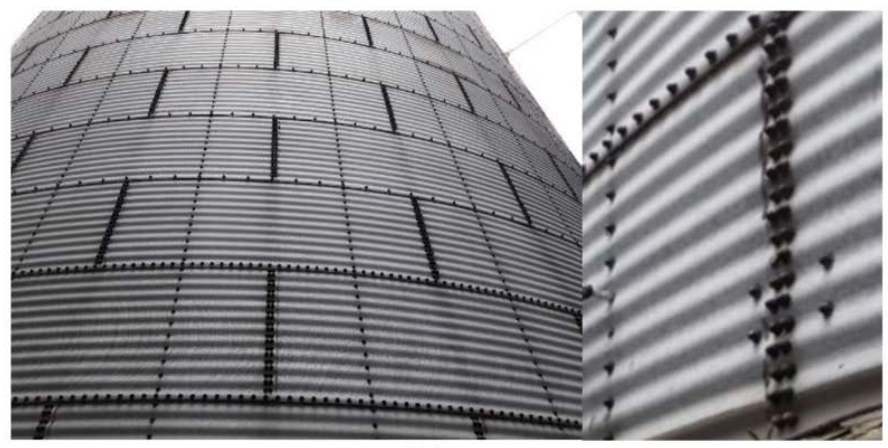

(a)

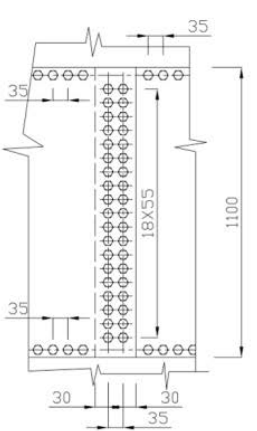

(b)

Gambar 2. (a) Struktur dinding silo, (b) Formasi baut antar panel dinding silo.

\subsection{Struktur Stiffener}

Struktur stiffener berfungsi untuk menghubungkan panel-panel dinding silo dalam arah vertical. Sambungan antara struktur stiffener dan dinding silo menggunakan baut M10 yang disusun berjajar dengan jarak antar baut 100 mm. Struktur stiffener diletakkan di dalam dinding silo (berada di dalam silo) sejumlah 40 stiffener. Geometri stiffener 
yang digunakan terdiri dari dua jenis, yaitu stiffner dengan sirip yang terpasang pada bagian paling bawah hingga ketinggian $3 \mathrm{~m}$ dan stiffner tanpa sirip yang terpasang di atas stiffner bersirip (di atas ketinggian $3 \mathrm{~m}$ ). Sambungan stiffner menggunakan plat penyambung yang diikat dengan sambungan baut. Geometri stiffner seperti ditunjukkan dalam Gambar 3.
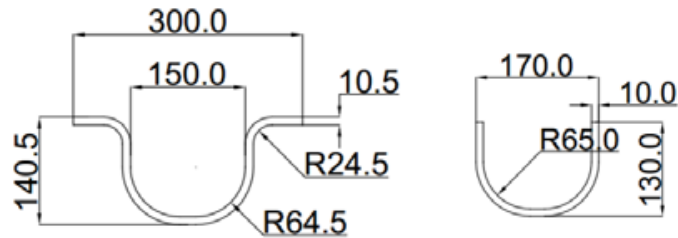

Gambar 3. (a) Dimensi struktur stiffener bersirip, (b) Dimensi struktur stiffener tanpa sirip.

\subsection{Pemodelan FEM}

Analisis FEM dilakukan untuk 2 jenis model dinding yang kemudian hasil analisis tegangannya dibandingkan. Model-model tersebut meliputi model dinding dengan ketebalan dinding 5 mm (Model 1) yang berada pada ketinggian 0-2m dan model dinding dengan variasi tebal, yaitu 5 dan 2,5 mm yang disusun membentuk dinding bertingkat (Model 2) yang berada pada ketinggian 1-3m. Untuk mengamati pengaruh sudut kemiringan dinding silo pada distribusi tegangan dinding, analisis FEM juga dilakukan dengan memvariasikan sudut kemiringan dinding silo. Pemodelan dilakukan pada 1/8 keliling lingkaran silo.

\section{Hasil dan Pembahasan}

Pada kondisi miring, struktur dinding silo mengalami beban gabungan yang berupa gaya desak dalam arah radial dan gaya berat grain dalam arah gravitasi. Perhitungan masing-masing beban diuraikan sebaai berikut:

\subsection{Gaya Desak}

Dalam paper ini, besarnya tekanan desak dinding dihitung dengan menggunakan formulasi tekanan statik yang berlaku pada fluida dengan memberikan faktor koreksi yang mewakili kemampuan alir serbuk pada arah lateral. Oleh karena itu gaya desak yang bekerja pada dinding silo dinyatakan dalam Persamaan 1, dimana konstanta kemampuan alir serbuk biji gandum sebesar 0,9. Gaya desak yang bekerja pada dinding silo diilustrasikan dalam Gambar 4.

$P=0,9 \cdot \rho_{\text {gandum }} \cdot g \cdot h$

dimana massa jenis gandum adalah $775 \mathrm{~kg} / \mathrm{m}^{3}$.

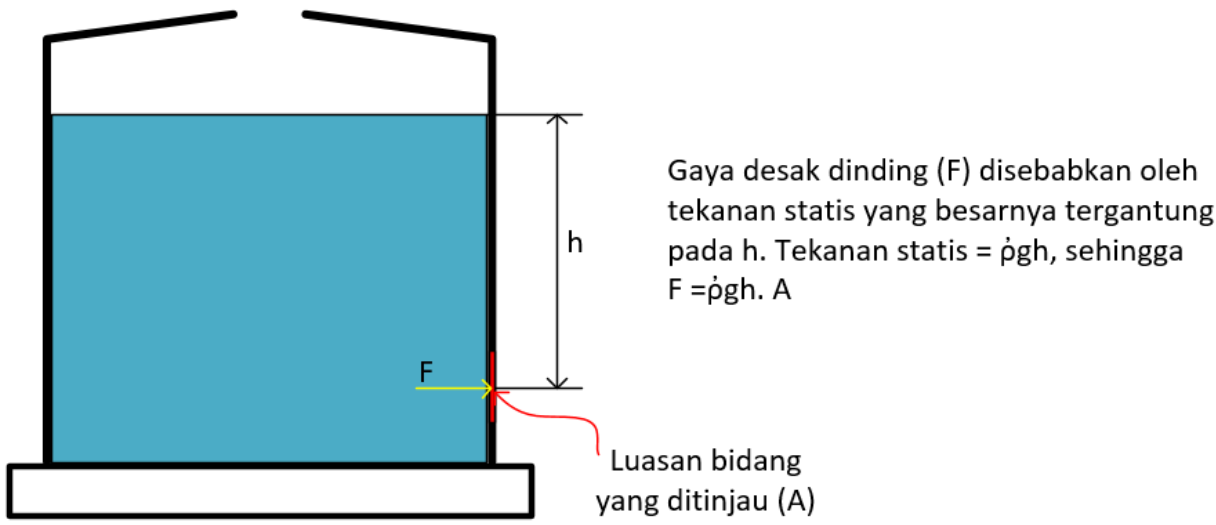

Gambar 4. Gaya desak dinding akibat tekanan kolom grain dalam silo.

\subsection{Gaya Berat Massa Tersimpan}

Dengan mengasumsikan silo terisi penuh (100\% kapasitas, 4650 ton) gaya berat massa tersimpan berupa massa yang ditahan oleh luasan dinding akibat kemiringan dinding seperti dituunjukkan dalam Gambar 5. Perhitungan massa yang ditanggung oleh panel dinding yang ditinjau terhadap fungsi kemiringan (ø) dapat didekati dengan Persamaan 2:

Massa $=\rho \mathrm{x}$ volume

dimana volume $=\sin \emptyset \times 2,9 \times(20,875-\cos \emptyset)$ 
Pada persamaan tersebut, lebar dinding yang ditinjau adalah $1 \mathrm{~m}$, sedangkan panjang dinding 2.9 m (merupakan dimensi satu panel dinding). Dengan menggunakan Persamaan di atas, maka massa yang ditanggung oleh panel dinding paling bawah sebagai fungsi kemiringan dinyatakan dalam Tabel 1.

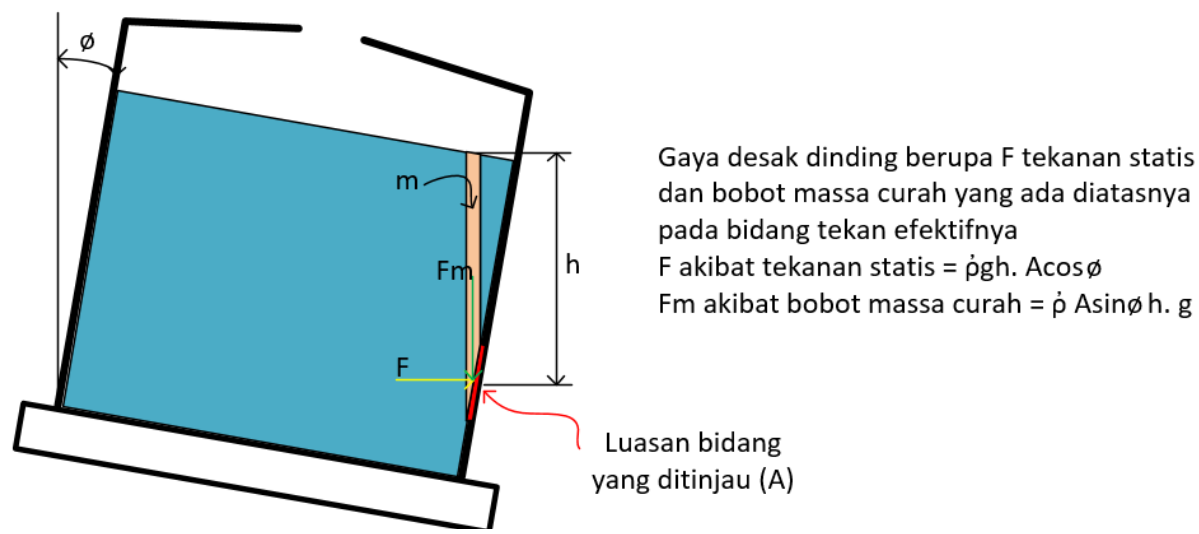

Gambar 5. Kondisi pembebanan dinding silo pada kondisi miring.

Dengan menggunakan persamaan di atas, hasil perhitungan massa yang ditanggung oleh dinding silo sebagai fungsi kemiringannya diuraikan dalam Tabel 1.

Tabel 1. Tambahan massa biji gandum pada satu panel dinding sebagai fungsi kemiringan silo

\begin{tabular}{|c|c|c|}
\hline KEMIRINGAN ( $\left.{ }^{\circ}\right)$ & VOLUME $\left(\mathrm{m}^{3}\right)$ & MASSA (kg) \\
\hline 5 & 5,02 & 3890 \\
\hline 10 & 10,02 & 7765 \\
\hline 15 & 14,94 & 11580 \\
\hline
\end{tabular}

Pemodelan dilakukan pada 1/8 lingkaran dinding silo, dengan distribusi beban sebagai berikut: struktur stiffener dikenai beban massa struktur dinding dan stiffener di atasnya setelah dikompensasi dengan sudut kemiringannya. Didasarkan pada data perhitungan di atas (Tabel 1), maka model pembebanan dinding silo seperti ditunjukkan dalam Gambar 6.

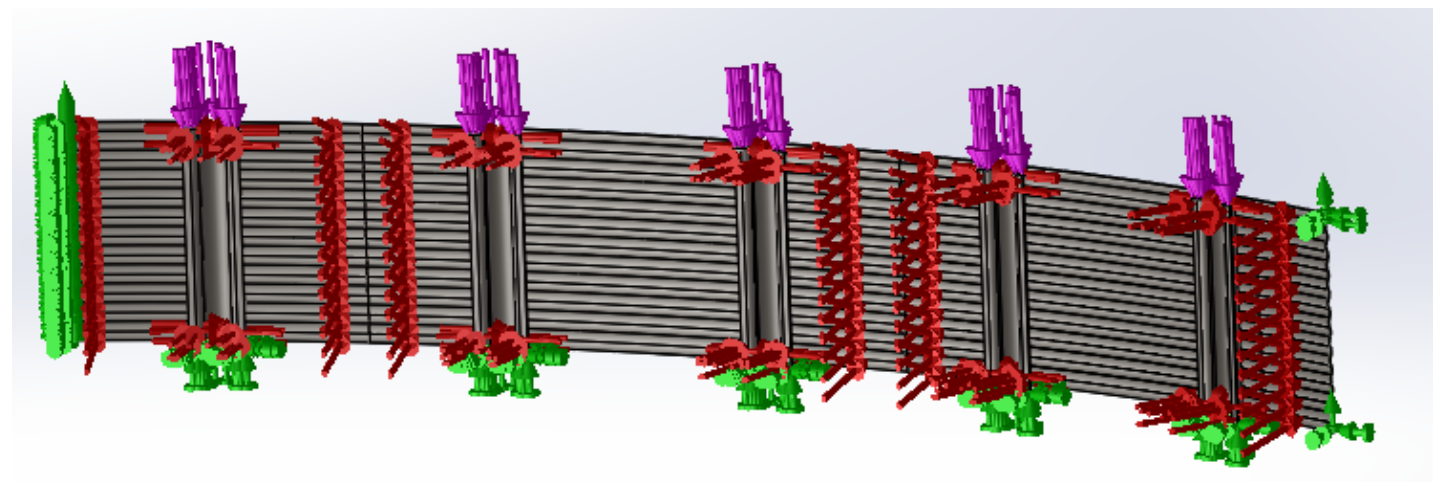

Gambar 6. Pola pembebanan konstruksi silo pada kemiringan $5^{\circ}$ (Model 1).

Hasil analisis FEM menunjukkan bahwa pada kemiringan $5^{\circ}$, tegangan maksimum yang terjadi pada dinding sebesar $7 \mathrm{~kg} / \mathrm{mm}^{2}$, yaitu pada sambungan baut antara stiffner dan dinding. Harga tegangan yang terjadi pada dinding menjadi sekitar 230\% dari tegangan pada dinding ketika silo dalam kondisi tegak. Hasil analisis FEM pada kondisi kemiringan silo $5^{\circ}$ ditunjukkan dalam Gambar 7. 


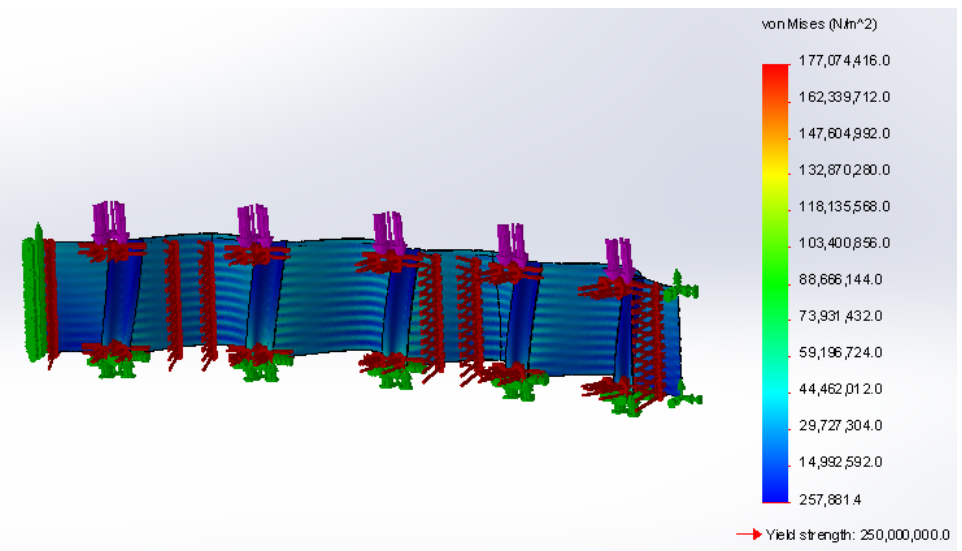

(a)

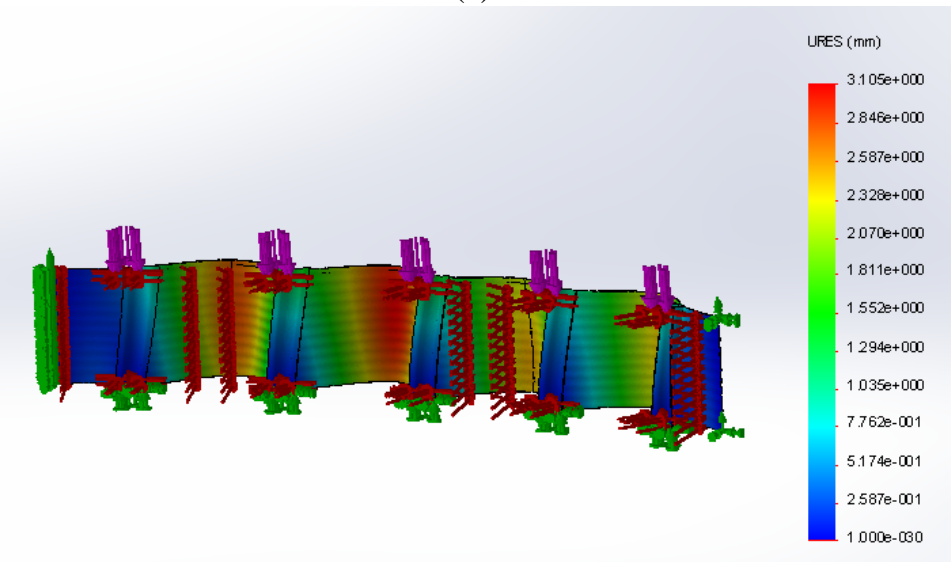

(b)

Gambar 7. (a) Distrubisi tegangan pada konstruksi silo dengan kemiringan $5^{\circ}$, (b) Deformasi dinding dan stiffener silo pada kemiringan $5^{\circ}$.

Gambar 8. Distribusi tegangan pada sambungan antara dinding silo dengan struktur stiffener.

Dengan prosedur yang sama, hasil simulasi FEM dengan variasi sudut kemiringan dinding silo untuk tegangan maksimum dan defleksi maksimum yang terjadi pada dinding silo diuraikan dalam Tabel 2.

Tabel 2. Tegangan dan deformasi maksimum hasil simulasi FEM untuk model dinding 1 dan 2

\begin{tabular}{clllll}
\hline \multirow{2}{*}{ SUDUT ( $\left.\mathbf{(}^{\mathbf{0}}\right)$} & \multicolumn{3}{c}{ MODEL $\mathbf{1}$} \\
& $\begin{array}{l}\text { Tegangan } \\
\left(\mathrm{kg} / \mathrm{mm}^{2}\right)\end{array}$ & $\begin{array}{l}\text { Meformasi maks } \\
(\mathrm{mm})\end{array}$ & $\begin{array}{l}\text { Tegangan maks dinding } \\
\left(\mathrm{kg} / \mathrm{mm}^{2}\right)\end{array}$ & $\begin{array}{l}\text { Deformasi maks } \\
(\mathrm{mm})\end{array}$ \\
\hline 0 & 13,6 & 1,68 & 24,4 & 5,21 \\
5 & 17,7 & 3,1 & 24,4 & 8,8 \\
10 & 51,3 & 9,04 & 44,4 & 16,9 \\
15 & 78,1 & 16,25 & 94,3 & 30,9 \\
\hline
\end{tabular}

\section{Kesimpulan}


Kondisi kritis struktur dinding silo terjadi di lokasi pertemuan antara dinding rangkap dan dinding tunggal (Model 2) pada ketinggian $2 \mathrm{~m}$, hal ini ditandai dengan lebih besarnya tegangan yang terjadi di lokasi tersebut dibandingkan tegangan yang terjadi pada dinding Model 1. Dampak kemiringan terhadap distribusi tegangan yang terjadi pada dinding silo relatif besar yaitu sekitar 5,7 x pada dinding Model 1 dan 3,8 x pada dinding Model 2 pada sudut kemiringan $15^{\circ}$.

\section{Daftar Pustaka}

[1] Gokalp, Z., Bundy, D.S., 2010, Analysis of Lateral Design Pressures, Vertical Frictional Forces and Bending Stresses on Horizontally Corrugated Steel Silo Wall Panels, GOU, Ziraat Fakultesi Dergisi, 27(2): 71-79.

[2] Goodey, R.J., Brown, C.J., Rotter, J.M., 2006, Predicted patterns of filling pressures in thin-walled square silos, Engineering Structure, 28: 109-119.

[3] Janssen, H.A., 1895, Versuche uber getreidedruck in silozellen, Zeitshrift des Vereines Deutscher Ingenieure, 39(35):1045-1049.

[4] Rotter, J.M., 2001, Guide for the economic design of circular metal silos, London: Spon Press.

[5] ACI 313-91., 1991, Standard practice for design and construction of concrete silos and stacking tubes for storing granular materials, Detroit: A, Erica Concrete Institute.

[6] DIN 1055., 1987, Design loads for buildings: Loads in silo bind, DIN 1055 part 6, Berlin: Deutsches Institut fur Normung.

[7] Airy, W., 1897, The Pressures of Grain, Minutes of Proceedings, Institution of Civil Engineers, London, Vol. 131, pp. 347-358.

[8] Jamieson, J.A., 1904, Grain Pressures in Deep Bins, Trans, Canadian Society of Civil Engineers, Vol. 17, pp. 554607.

[9] Reimbert, M., Reimbert, A., 1976, Silos- Theory and Practice, Trans. Tech Publications, Clausthal Zellerfeld, West Germany.

[10] Molenda, M., Montross, M., Thompson, S.A., Horabik, J., 2009, Asymmetry of Model Bin Wall Loads and Lateral Pressure Induced from Two- and Three Dimensional Obstructions Attached to the Wall, Transactions of the ASABE, 52(1): 225-233. 